\title{
KÖTÜLÜK OLGUSUNA İLAHİ YASALAR BAĞLAMINDA BAKIŞ
}

\author{
Prof. Dr. Metin ÖZDEMIR \\ Yıldırım Beyazıt Ü. İslami İlimler Fakültesi, Ankara, TURKEY \\ ozdemirmetin@hotmail.com
}

\section{Özet}

Yeryüzünde meydana gelen tüm olaylar, Allah'ın her şeyi kuşatan bilgisinin ve sonsuz hikmetinin bir gereği olarak koymuş olduğu yasalar doğrultusunda gerçekleşir. Hiçbir olay ve hiç kimse bu yasaların dışına çıkamaz. Allah, insana bu yasaları keşfetme imkân ve kabiliyetini vermiştir. $\mathrm{O}$ halde insana düşen bu yasaları keşfetmek için gereken adımları atmaktır.

İnsanın başına gelen kötülük ve musibetler, bazen kendi hatası bazen de imtihan sırrının bir gereği olarak gerçekleşir. Bunların hepsi, belli bir yasaya göredir. İnsan, başına gelen kötülük ya da musibetlerin hangilerinin kendi hatası, hangilerinin de kendi elinde olmayan nedenlerle gerçekleştiğini ayırt edebilecek bir temyiz gücüne sahiptir. Bu yüzden kendi sorumluluğunu kadere fatura etmek için mazeret ileri sürme hakkı onun elinden alınmıştır.

Bu tebliğimizde yukarıda çerçevesi oluşturulan kelamî/teolojik yaklaşımın aklî ve naklî temellerini sunmaya çalışacağız.

Anahtar Kelimeler: Kötülük, İlahi Yasa, Takdir, Sebep-Sonuç, Sorumluluk, Hikmet 


\title{
THE OVERVIEW ON THE PHENOMENON OF EVIL IN THE CONTEXT OF THE DIVINE LAWS
}

\begin{abstract}
All the events that have occurred on the Earth take place as a requirement of God's infinite knowledge that surrounds everything and his wisdom in accordance with the laws that he had put. No event and no one can step outside of the law. God has given human beings the ability to discover these laws. Then the first step required for human is to explore these laws.

The evil and calamities that exposed to people happen sometimes by their own fault and sometimes as a requirement of the secret exam of The Creator. All these are relative to a particular law. People have the power to distinguish between the events that have come to them because of their actions and the events that occurred because of the God ordered them as like they are. For this reason, the excuse to refuge to God's predestined order/qadar is not justified for them.

In this presentation we will try to offer the rational and traditional basics of this theological approach that has been formed above its framework.
\end{abstract}

Keywords: Evil, Divine Law, Predestination, cause-and-effect, Responsibility, Wisdom 


\section{Giriş}

\section{Kavramsal Çerçeve}

\section{Kötülük}

İnsan, fitratı gereği kötülüğü objektif bir şekilde tanımlama yeteneğine sahiptir. ${ }^{1}$ Kötülük; en basit ifadesiyle iyinin karşıtı olan şeydir. İnsan, her ne kadar bazen kendisi için yararlı olan, hoşuna giden, kendisine haz ve zevk veren şeyleri iyi olarak görse de karşısına çıkan tüm olgu ve olayları aklı ve fitratından hareketle değerlendirdiğinde, iyinin; övülen, kabul gören ve beğenilen bir şey olduğunu bilir. O halde kötülük, ortak aklın ve vicdanın yerdiği, kabul etmediği ve hoşlanmadığı bir şeydir. Bu yüzden Kur'an, bize iyiliği emrederken onun bir tanımını vermez. Çünkü Kur'anî öğretiye göre insan, iyi ve kötüyü ayırt edebilecek bir yaratılışa/fitrata sahiptir. ${ }^{2}$

Müslüman filozofların bakış açısına göre ise kötülü̈̆ün, dış dünyada parmağımızla işaret ederek gösterebileceğimiz somut bir varlığ1 yoktur. Bununla birlikte kötülüğü pek çok kılıkta görebiliriz. Hepsinin ortak noktası bize zarar veriyor olmalarıdır. Kötülük bazen yolumuzu kesen bir eşkıya bazen de merhametsiz bir yürek oluverir. Ama onun dokunabileceğimiz, görebileceğimiz bir bedeni ya da işitebileceğimiz bir sesi yoktur. Bu yüzden filozoflara göre kötülük, yokluktan/ademden ibarettir. Burada yokluk kavramıyla kötülük kavramının hiçbir anlamsal içeriğinin bulunmadığı kastedilmemektedir. Aksine kötülüğün; sadece iyiliğin, kemalin ve yetkinliğin yokluğundan ibaret olduğuna işaret edilmektedir. Onlar açısından bir şey kötü dediğimiz zaman, anlamamız gereken şey, onda yeterli ölçüde iyiliğin bulunmadığıdır. Dolayısıyla iyiliğin hiç bulunmadığı bir durumda, mutlak kötülükten ziyade mutlak yokluktan söz edilebilir. O halde; bir şey var olduğu sürece; orada sadece yeterli ölçüde iyiliğin bulunmadığından söz edebiliriz.

Kötülüğün bu şekilde tanımlanması, oldukça iyimser bir yaklaşım olmakla birlikte, o hemen bir kenara bırakılabilecek bir tanım olarak da gözükmemektedir. Nitekim en kötü olarak gördüğümüz şeyin bile bir iyi tarafı olduğunu söyleyebiliriz. En kötü; bize en iyinin anlamını ve değerini öğretir. Bu yönüyle onun varlığında, bir yönüyle de olsa iyiliğin bulunduğundan söz edebiliriz. Kötülüğü yokluk olarak tanımlayan filozoflara göre en kötü; bir anlamda en az iyinin bulunduğu varlık türü olmaktadır. Sonuç olarak söylemek gerekirse, onlara göre kötülük; salt yokluktan ya da eşyanın kemalinin yokluğundan ibarettir. Kısacası, yokluk, salt kötülüktür. ${ }^{3}$

\footnotetext{
${ }^{1}$ Kötülüğün farklı tanımları için bkz., İbn Manzur, Lisânu'l-Arab, Beyrut 1990, IV/400; Murtazâ ez-Zebidî, Tâcu'l-Arûs, tahkik: Ali Sînî, Beyrut 1994, VII/16; Tehanevî, Keşşâfu Istılahâti'l-Fünûn, Beyrut, ts., I/417.

${ }^{2}$ Rum 30/30; eş-Șems 91/8.

3 İbn Miskeveyh, Risâle Fî Mâhiyeti'l-Adl, E. J. Brill, Leiden 1964, s. 13; Fârâbî, et-Ta'likat, Haydarabad 1346H., s. 11; İbn Sinâ, eş-Şifâ (İlahiyat, tahkik: Ebu Kanvâtî, Sa'îd Zâyid), trs., s. 416; İzmirli İsmail Hakk1, Yeni Ilm-i Kelam, hazırlayan: Sabri Hizmetli, Ankara 1981, s. 336.
} 


\section{KÖTÜLÜĞÜN KISIMLARI}

Kötülük; kaynağı itibariyle, metafiziksel ve ahlâkî olmak üzere iki kısma ayrılır.

\section{Metafiziksel Kötülük}

Metafiziksel kötülük en genel anlamıyla, eşyanın kemal ve yetkinlik bakımından eksik olmasıdır. ${ }^{4}$ Filozoflar açısından bu eksikliğin sebebi, Tanrının yüce hükümranlığının, bütün olası hükümranlık ve yönetimlerin en üstünü olması hasebiyle, orada çok sayıda iyiliğin tam olarak gerçekleşebilmesi için az sayıda kötülüğün bulunmasının kaçınılmaz olmasıdır."

Kelamcılar ise; metafiziksel anlamdaki kötülük olgusuna; hikmet kavramı çerçevesinden bakarlar: Onlara göre; Allah isteseydi, hiçbir kötülüğün bulunmadığ 1 bir dünya yaratabilirdi. Nitekim Cennet böyle bir yerdir. Ama $\mathrm{O}$, hikmeti gereği bu dünyayı bir imtihan alanı kılmış; bunun doğal bir sonucu olarak da orada bir takım kötülüklerin bulunmasına izin vermiştir ki; böylece aklı ve vicdanıyla iyi ve kötünün arasını ayırt edebilme yeteneğine sahip olan insan; kendi hür iradesiyle yapmış olduğu seçimlerinin sorumluluğunu yüklenmiş olabilsin.

Metafiziksel kötülükler, eşyanın ve canlıların doğasına yerleşmiş vaziyette bulunan kötülüklerdir. Örneğin, çöller ve buzullarla kaplı bölgeler; tehlikeli av hayvanları; akrepler ve yılanlar gibi yaratıklar, dev dalgalar, volkanlar, kuraklık ve kıtlık gibi insanların peşini bırakmayan ve onlara sınırsız acılar çektiren felaketler; cüzam, kanser ve çocuk felci gibi onlara istırap çektirip zarar veren ürkütücü hastalıklar bu türden kötülüklerin listesini oluştururlar. ${ }^{6}$

Kısacası, metafiziksel kötülük olarak nitelendirilen şeyler, eşyanın doğasında bulunan birtakım eksikliklere bağlı olarak ortaya çıkan; olumsuz ve istenmeyen sonuçlara yol açan olaylar ve fiillerden ibarettir. Bu durum, sadece imtihan sırrının bir gereği olarak ortaya çıkmıştır. Yoksa Allah, isteseydi, hiçbir kötülüğün bulunmadığ 1 bir dünya da yaratabilirdi. Allah'ın insanı imtihan etmesindeki hikmetler ise bu konunun temel meselelerinden birisi olduğundan, ona daha sonra ayrıntılı bir şekilde değinilecektir.

\section{Ahlakî Kötülük}

Ahlakî kötülük kavramıyla daha çok; ayıplar, kusurlar, hata, yalan, düşmanlık, bencillik, kıskançlık, hırs, zulüm, merhametsizlik, korkaklık ve daha geniş anlamda savaşlar ve onlarda yaşanan gaddarlıklar gibi kötülükler kastedilmektedir. ${ }^{7}$ İbn Miskeveyh ise onu doğrudan insan iradesi ile ilintilendirerek "insanın kendi iradesi, çabası, tembellik veya ilgisizliğiyle iyiliklere ulaşmasını engelleyen şey" ${ }^{8}$ olarak tanımlar.

Ahlakî kötülüğü bir yönüyle metafiziksel kötülük ile ilişkilendirmek mümkündür. Çünkü her ne kadar o, insan iradesine bağlı olması yönüyle ahlâkî bir problem olarak görülebilirse de, bizzat insanda kötülüğe yönelme eğiliminin yaratılmış olması bakımından metafiziksel bir problem olarak da düşünülebilir.

\footnotetext{
${ }^{4}$ el-Mu'cemu'l-Felsefi, Mecmeu'l-Lugati'l-Arabiyye, 1983, s. 102.

5 İbn Sina, Necât, tahkik: Abdurrahman Umeyra, Beyrut 1992, II/147; eş-Şifâ (İlahiyat), s. 418; John Hick, Classical and Contemporary Readings in The Phlosophy of Religion, London 1964, s. 70.

${ }^{6}$ Nelson Pike, God and Evil, Prentice-Hall, New Jersey 1964, s. 63; Michael Peterson, William Hasker, Reason and Religious Belief, Oxford 1991, s. 93; Jeffrey Burton Russell, Şeytan, İstanbul 1999, s. 20-23.

7 el-Mevsû'atü'l-Felsefe, I/511; Nelson Pike, God and Evil, s. 7 vd.; Brian, Davies, An Introduction To the Philosophy of Religion, Oxford 1981, s. 20; Michael Peterson, Reason, s. 92. 
Ahlakî kötülük; kısaca, insanın kasıtlı olarak kötü olana yönelmesi şeklinde tanımlanabilir. Doğal olarak bu tür bir yönelişten kaynaklanan tüm kötülükler, ahlâkî kötülük başlığı altında listelenir.

\section{İLAHİ YASA/SÜNNETULLAH}

Sünnet; lügatte, bir otorite tarafindan belirlenen ve konulan yasa, kanun ve izlenen yol ve metot $^{9}$ gibi anlamlara gelmektedir. Kur'an'da ise bu kavram genel olarak Allah' ın koyduğu yasa, verdiği hüküm ${ }^{10}$, Onun doğal ve toplumsal olaylardaki uygulaması ve âdeti gibi anlamlara gelir. ${ }^{11}$ Kisacası o, Allah'ın doğada ve toplumda koyduğu kanunu ve düzeni demektir. Kur'an'da, sünnetullah tabiriyle genel olarak "Allah'ın yaratma ve yönetmesinde öteden beri süregelen ve değişmeyen uygulamasının bulunduğuna işaret edilmiştir." 12

$\mathrm{Bu}$ açıdan bakıldığında yaratılan her şeyin, Allah'ın yaratış tarzı olan bu sünnete/modele uygun olduğunu söyleyebiliriz. Onun yaratış tarzı ise tümüyle hikmettir. Dolayısıyla yaratılan ve var olan her şey, kendisine en uygun olan yere yerleştirilmiştir. Bu, Allah'ın Yasasıdır ve buna teslimiyet, uyum ve ahenk getirir. Bunun tersi ise uyumsuzluk ve ahenksizliğe yol açar. Çünkü bu, insanın hakiki doğası ve tabiatta yerleşik olanın dışında başka bir şeyi idrak etmek anlamına gelir. ${ }^{13}$

\section{KÖTÜLÜK OLGUSUNA İLAHİ YASALAR BAĞLAMINDA BAKIŞ}

\section{Illahî Yasaların Değişmezliği ve Sürekliliği}

Allah yeryüzünde meydana gelen tüm olayları, Kendisinin her şeyi kuşatan bilgisinin ve sonsuz hikmetinin bir gereği olarak koymuş olduğu yasalar doğrultusunda gerçekleştirir. Kur'an bu yasaların en belirgin özelliklerinden birisinin değişmezlik ve süreklilik olduğunu 1srarla belirtir. ${ }^{14} \mathrm{Bu}$ durumun bir istisnası olan mucizeler, belli bir amaca yönelik özel durumlardır ve çok nadir olarak gerçekleşirler. Ancak onların da olağan olayların bağlı oldukları yasaların üstünde daha gelişmiş ve mükemmel yasalara bağlı oldukları söylenebilir. Kur'an'daki Ashab-ı Kehf hikâyesinin içeriği ${ }^{15}$ bu duruma açık bir şekilde işaret etmektedir.

Kur'an'da tabiat olaylarının rast gele değil, belli sebeplere ve yasalara bağlı olarak gerçekleştiğini gösteren onlarca ayet vardır. Örneğin rüzgârlar, yağmur yüklü bulutları belli yörelere sürüklerler ve sonuçta oralara yağmur yağar. Ardından ölü toprak yeşerir. ${ }^{16}$ Tüm bunların ötesinde, Kur'an, Allah'ın canlı ve cansız yaratığı her şeye nasıl davranacağını gösterdiğini, yani onların hepsi için belli davranış yasaları koyduğunu net olarak söyler. Nitekim Hz. Musa, Kendisine ve kardeşi Harun'a “sizin Rabbiniz de kimdir" diye sorun Firavun'a şöyle cevap verir: "Rabbimiz her şeye ayrı bir yaratılış özelliği veren sonra da

9 İbn Manzûr, Lisânu'l-Arab, Beyrut 1414 H., XIII/225-226.

10 ez-Zerkeşî, el-Burhân fî Ulûmi 'l-Kur'ân, tahkik: Muhammed Ebu'l-Fadl İbrahim, Beyrut 1391 H., I/413.

11 el-Maverdî, en-Nüket ve'l-Uyûn, tahkik: es-Seyyid İbnu Abdi'l-Maksud bin Abdirrahim, Beyrut, trs., V/318.

12 İyas Çelebi, "Sünnetullah", DİA, İstanbul 2010, XXXVIII/159.

13 S. Nakib Attas, İslami Düşünüşün Problemleri, İstanbul 1989, s. 88.

14 el-Ahzab 33/62; Fâtır 35/43; el-Feth 48/23.

15 el-Kehf 18/9-26.

16 en-Neml 27/60-64. 
onlara nasıl davranacaklarını ${ }^{17}$ gösterendir." ${ }^{18}$ Allah bu yasaları her varlığa kendisine uygun olan bir lisan ile bildirir. Dolayısıyla cansız varlıklar için geçerli olan söz konusu yasaları, onların yaratılış özelliklerinden hareketle okumamız ve anlamamız mümkündür.

Evrendeki hiçbir varlık bu yasaların dışına çıkamaz. Allah, insanı bu yasaları keşfedebilecek bir imkân ve kabiliyetle donatmıştır. O halde insanın temel görevlerinden birisi de bu yasaları keşfetmek için gereken adımları atmaktır. İnsan bu yasaları azimli ve kararlı çalışmalarının sonucunda keşfedebildiği ölçüde tabiatta, Yaratıcısı tarafindan kendi hizmetine sunulan varlıkları boyunduruğu ve egemenliği altına alabilecektir. ${ }^{19}$ İnsanlık tarihi içinde yaşanan tecrübeler bize bunun sayısız örneklerini sunmaktadır. Bu yüzden Kur'an, ilahî yasaların değişmezliğini ve sürekliliğini vurguladığı ayetlerde, tarihsel olayların bunun kanıtı olduğuna dikkatlerimizi çeker. ${ }^{20}$ Dolayısıyla sosyal alanda belli yasaların değişmezliği ve sürekliliğinin en somut kanitı tarihtir. Tarihsel olaylarda görülen sebeplerle sonuçlar arasındaki ilişski, gelecekte de benzer sebeplerin benzer sonuçları doğuracağını açıkça göstermektedir. Kur'an'da Tarihsel ve sosyal olaylarda görülen sebep-sonuç ilişkisini en açık bir biçimde dile getiren ayetlerden birinde şöyle buyurulur: "Bir toplum kendi durumunu değiştirmedikçe Allah onların durumunu değiştirmez...",21

$\mathrm{Bu}$ ayet bize, yalnızca tabiat olaylarının değil, sosyal olayların da belli yasalara tabii olduğunu kanıtlamaktadır. Aklî ve tecrübî veriler de bunu teyit etmektedir. İnsanoğlu bu yasaları tespit etmek suretiyle problemlerinin kaynağını ve çözüm yollarını öğrenme imkânı bulur.

\section{Kötülük ve Musibetlerin İlahî Yasalarla İlişkisi}

Tabiat olaylarının doğurduğu sonuçları, insanın eylemlerinden tamamen ayrı olarak düşünmek mümkün değildir. Çünkü hem akıl ve tecrübe hem de Kur'an bu ikisi arasındaki sıkı ilişkinin varlığını açıkça göstermektedir. Bu itibarla insanın başına gelen musibetlerin doğurduğu olumsuz sonuçların, onun kendi hatası ile doğrudan bir ilişkisi söz konusudur. Bu ilişkiye bağlı olarak ortaya çıkan sonuçların hepsi, belli bir yasaya göredir.

İnsan, başına gelen kötülük ya da musibetlerin hangisinin kendi hataları, hangisinin de kendi elinde olmayan nedenlerle gerçekleştiğini ayırt edebilecek bir temyiz gücüne sahiptir. Örneğin, bir maden ocağında gerçekleşen ve yüzde yüz insan hatasına bağlı olarak gerçekleşmiş bir grizu patlaması ve doğurduğu trajik sonuçları ele alalım. Eğer bu olay, oluş tarzı itibariyle tamamen önlenebilir bir karakter taşıyorsa, bilirkişinin, 'gerekli tedbirler alınmış olsaydı, ne bu olay ne de doğurduğu trajik sonuçlar gerçekleşirdi' şeklinde verdiği rapor, bir tabiat olayıyla insan fiilleri arasındaki ilişkiyi yöneten yasaları açıkça ortaya koymaktadır. Tabiat, Yaratıcısı tarafından çeşitli hikmetlere bağlı olarak grizu patlaması olayının gerçeklemesine uygun bir özellikte yaratılmıştır. Dolayısıyla Yaratıcı, bu olayın gerçekleşebilmesi için gerekli olan şartları ve yasaları belirlemiştir. Söz konusu potansiyel olayın, bu yasalara bağlı olarak bilkuvve halinden bilfiil haline geçişi, eğer doğrudan insan fiillerine bağlı ise o zaman bu olayın ve muhtemel sonuçlarının nihai nedeni, tabiatı bu şekilde Yaratan yaratıcı değil, buna doğrudan sebep olan insandır.

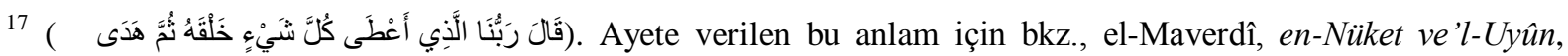
III/406.

${ }_{18}^{18}$ Taha 20/50.

${ }^{19}$ Cevdet Said, Bireysel ve Toplumsal Değişmenin Yasalarl, ikinci baskı, İstanbul 1986, s. 14.

20 el-Feth 48/23.

${ }^{21}$ er-Ra'd 13/11.
} 
$\mathrm{Bu}$ yüzden insanın kendi sorumluluğunu kadere fatura etmek için mazeret ileri sürme hakk1 elinden alınmıştrr. Nitekim Allah, kâfirlere kıyamet gününde şöyle hitap edecektir:

"Ey inkâr edenler! Bugün özür beyan etmeyin; ancak işlediklerinizin karşıllı̆̆ın görmektesiniz. ,"22

İnsanın hem bu dünyada hem de ahirette kendi hatalarının faturasını ödemesi ilahi bir yasadır. $\mathrm{Bu}$ yüzden kâfirler ve müşriklerle yapılan harpte kısmî bir yara alan müminlere Cenabı Hak şöyle hitap etmektedir:

[Bedir'de] iki katın [düşmanınızın] başına getirdiğiniz bir musibet, [Uhud'da] kendi başınıza geldiği için mi 'Bu nasıl oluyor!' dediniz? De ki: 'O, kendi kusurunuzdandır. Şüphesiz Allah'in her şeye gücü yeter. ",

$\mathrm{Bu}$ gerçek başka bir ayette genel bir yasa olarak şöyle ifade edilir:

"Başınıza gelen herhangi bir musibet, ellerinizle işlediklerinizden ötürüdür. O, yine de çoğunu affeder. "24

Sonuç itibariyle, başımıza gelen her şey bu ilahi yasalar çerçevesinde gerçekleşmektedir. Şiddetli depremler kadar, onların yıkıcı ve öldürücü sonuçlarından korunmak da bu yasaların içindedir. Nitekim şiddetli depremler, Japonya gibi bu yasaları keşfedip binalarını onlara göre yapan gelişmiş ülkelerde; artık büyük ölçüde yıkıcı ve öldürücü olmaktan çıkmışır.

\section{Felaketler ve Musibetlerin İlahi Ceza İle İlişskisi}

İyi ve kötü her olay bir imtihan vesilesidir. Bazen yeryüzünün, yaratıllştan kaynaklanan özellikleri dolayısıyla bazı bölgeleri deprem olaylarına daha yatkın olabilir. İnsanlardan bazıları bilmedikleri için evlerini bu tür bölgelerde yer alan fay hatları üzerine bina etmiş olabilirler. Doğal sürecin nasıl işleyeceğini belirleyen ilahi takdire bağlı olarak bu fay hatları harekete geçip deprem olduğunda; buradan o yöre halkının Allah tarafindan cezalandırıldığ sonucu çıkarılamaz. Eğer insanlar bu fay hatlarını tespit edip evlerini oradan uzak bölgelerde depreme elverişli bir şekilde yaparlarsa, bu tür felaketlerin muhtemel yıkıcı ve öldürücü sonuçlarından korunabilirler.

Elbette Allah dilerse, kulları ne kadar güçlü ve etkili tedbirler alırlarsa alsınlar onları cezalandırabilir. Onun gücüne karşı çıkabilecek hiçbir güç yoktur. Helak edilen kavimlerin durumları, bu gerçeğin açık örnekleridir: Ad kavmi kayaları oyarak son derece sağlam binalar yapmış olmalarına rağmen Allah'ın azabından korunamadılar. Fakat bu, alınan tedbirlerin başa gelebilecek felaketlerin zararlarını önlemede etkili olmayacağı anlamına gelmez. Çünkü her felaket, cezalandırma maksadıyla gelmez. Belki çoğu doğal bir sürecin neticesidir ve her biri birer imtihan vesilesidir. Bu nedenle herkes elinden geldiği kadarıyla takdirin içinde olan tedbiri almaktan sorumludur.

Takdirin içinde olan tedbirle; Allah'ın her konuda kullarına vermiş olduğu imkânları kastediyoruz. Örneğin deprem gibi büyük felaketlerin yıkıcı ve öldürücü sonuçlarını önleyebilmek için alınabilecek tüm tedbirler, bu imkânların bir parçasıdır. O halde depremler gibi büyük felaketler, ilahi bir yazgıdır. Çünkü bu tür olaylar, insan iradesini aşmaktadır. Onlar, sonsuz ilahi hikmetin gerektirdiği doğrultudaki imtihan sırrının şartlarına bağlı olarak

\footnotetext{
22 et-Tahrim 66/7.

23 Âl-i İmran 3/165.

${ }^{24}$ eş-Şura 42/30.
} 
gerçekleşmektedirler. Bu itibarla depremler doğrudan ilahi, onların sonuçları ise doğrudan beşeri, dolaylı olarak ise ilahi iradeye bağlıdırlar. Dolayısıyla hepsi ilahi takdir içerisinde kendisine ait olan yönleriyle yer almaktadır.

İlahi yasaları bu çerçevede değerlendirmemiz gerekir. Onlar, bir yönüyle ilahi, diğer bir yönüyle ise beşeri iradeye bağlı olarak gerçekleşirler. Elbette insan yalnızca kendi iradesine bağlı olan yönlerden sorumludur.

Bununla birlikte bazı felaketler ve musibetler doğrudan ilahi bir ceza olarak gelirler. Bu tür felaketlerde de sonuç itibariyle belirleyici olan toplumların iradesidir. Kur'an'1 Kerim bunun açık örnekleriyle doludur. Örneğin helak edilen kavimlerin durumlarına işaret eden bir ayette şöyle denmektedir:

"Kendilerinden önce olan Nuh, Ad, Semud milletlerinin, İbrahim milletinin, Medyen ve altüst olmuş şehirler halkının haberleri onlara gelmedi mi? Peygamberleri onlara belgeler getirmişlerdi. Allah onlara zulmetmemiş, onlar kendilerine yazlk etmişlerdir. ",25

Zulümde ve Allah'a karşı başkaldırıda aşırı gidenlere, belki uslanırlar diye belli bir süre firsat tanınır. Sonra eskiden beri uygulana gelen ilahi yasa devreye girer ve hepsi birden helak edilir. Onlar kendi iradeleriyle musibeti üzerlerine çekmişlerdir. Kavimler ve halklar, günah işlemekte sınırları aştıklarında hep aynı ilahi yasa devreye girer. Sonuç her zaman korkunç bir felaketle yok olmaktır:

"Her birini günahı sebebiyle yakaladık; kimine taşlar savuran rüzgârlar gönderdik, kimini bir çı̆̆llk yok etti, kimini yerin dibine geçirdik, kimini de suda boğduk. Onlara, Allah zulmetmiyordu, fakat onlar kendilerine yazlk ediyorlardl.,"26

$\mathrm{Bu}$ tür durumlarda, insanlar en yüksek teknolojiyi de kullansalar, ilahi irade ve kudretin karşısında duramazlar. İlahi yasa da daima, zulümde ve isyanda haddi aşan toplumların helaki şeklinde tecelli eder:

"Yeryüzünde dolaşıp, kendilerinden önce geçmiş kimselerin sonlarının nasıl olduğuna bakmazlar mı? Ki onlar kendilerinden daha kuvvetli idiler, yeryüzünü kazıp alt üst ederek onlardan çok imar etmiş kimseydiler ve onlara belgelerle peygamberler gelmişti. Böylece Allah onlara zulmetmiyor, onlar kendilerine zulmediyorlardl. ",2

Görüldüğü üzere sonuç hiç değişmemektedir. Her hâlükârda insanın başına gelen tüm felaket ve musibetler, kendi elleriyle işledikleri yüzündendir. İnsanlar, birer imtihan vesilesi olan felaketlerde gerekli tedbirleri almamaları ya da başkalarının iradelerini kötü yönde kullanmaları sonucu zararlı, yıkıcı ve öldürücü sonuçlarla karşılaşır. Birer ceza olarak gelen felaket ve musibetlerde de yine belirleyici olan faktör, helak edilen bireylerin ya da kavimlerin zulümde haddi aşmaya yönelen iradeleridir.

\section{Başkalarının Hatasının Biżm Felaketimiz, Olmasının İlahi Yasalarla İlişkisi}

$\mathrm{Bu}$ bağlamda, başkalarının iradelerini kötü yönde kullanmaları sonucu başımıza gelen felaketler kafamızı karıştırmamalıdır. Kurallara uyan bir sürücünün, onları ihlal eden sorumsuz başka bir sürücünün karıştığı bir kazada büyük zarar görmesi de bir musibettir. Bu musibetin sorumlusu, iradesini kötü yönde kullanan sürücüdür. Cenabı Hak, imtihan sırrının

\footnotetext{
25 et-Tevbe 9/70.

${ }^{26}$ el-Ankebut 29/40.

27 er-Rum 30/9.
} 
bir gereği olarak insanların iradelerini istedikleri yönde kullanmalarına izin vermiştir. Ancak bu tür durumlarda, sorumlular hem bu hem de öbür dünyada hak ettikleri cezalarını bulacaklardır. Dolayısıyla insanın kendi hatası dışında başına gelen felaketleri ve musibetleri, imtihan sırrının doğal sonuçları olarak görmek gerekir. Bu tür durumlarda karşılaşılan zararlar ve kötü sonuçlar, bu dünyada olmasa bile öbür dünyada mutlaka telafi edilecektir.

Ancak masum insanların, başkalarının iradelerini kötü yönde kullanmasından kaynaklanan felaket ve musibetlerden zarar görmesi dahi tedbir-takdir ilişkisi belirleyen yasalar çerçevesinde yer almaktadır. Örneğin iradelerini kötü yönde kullanan kişilere caydırıcı cezalar verilmesi, bütünüyle olmasa bile bu tür olayları büyük ölçüde azaltmak için yeterli olabilir. Dolayısıyla Kur'an'ın hırsızlık, haksız yere adam öldürme ve rızık endişesiyle çocukların öldürülmesi gibi suçlara ağır cezalar öngörmesini bu doğrultuda anlamak ve değerlendirmek mümkündür.

Sonuç itibariyle masum insanların başkalarının hataları yüzünden zarar görmesi, caydırıcı cezalar gibi çeşitli önlemler alınmak suretiyle önlenebilir ya da mümkün olan en asgari düzeye indirilebilir. Bu konuda da insanın tercihlerinin ve eylemlerinin ilahi yasa kapsamında sonuç verdiğini söylememiz mümkündür. Dolayısıyla insan için bu konuda da geçerli olan ilahi yasaları keşfedip ona göre hareket etme zorunluluğu vardır.

\section{İlahî Yasalara Bağlı Olarak Gerçekleşen Felaketlerin Beşerî İrade İle İlişskisi}

Bu bağlamda bütün felaket ve musibetlerin insan iradesine bağlı bir yönü var mıdır? Beşeri iradenin hiçbir etkisi olmadan, doğrudan ilahi iradeye bağlı olarak başımıza gelen felaketler yok mudur, şeklinde sorular yöneltilebilir.

$\mathrm{Bu}$ tür sorular, sebep-sonuç ilişkisinin egemen olduğu bir imtihan dünyasında yaşadığımızı unutmamızdan kaynaklanmaktadır. Her sonucun bir sebebinin olması da değişmez bir ilahi yasadir:

\section{“Şüphesiz Biz her şeyi bir ölçüye göre yaratmışızdır. ,28}

Evrende gerçekleşen her şey, belli bir ölçüye/yasaya göredir. Kendiliğinden olan hiçbir şey yoktur. Her sonuç, mutlaka bir sebebe bağlıdır. Allah'ın yaratmasında asla bir düzensizlik ve boşluk yoktur:

“Gökleri yedi kat üzerine yaratan O’dur. Rahman'ın bu yaratmasında bir düzensizlik bulamazsin. Gözünü bir çevir bak, bir çatlak görebilir misin?”,29

Her şeyin belli bir ölçüye, yasaya ve sebebe bağlı olarak gerçekleştiği bir dünyada, bir çocuk ölmüşse, sebepsiz değildir. Masum bir çocuğun ölümü bir sonuçtur. Dolayısıyla onun ölümünün mutlaka bir sebebi vardır. İnsan, bu sebebi bulup ona karşı önlem almaktan sorumludur. Aldığı önlemler, her zaman sonuç vermeyebilir. Ama akıl ve tecrübe, bize bazı ölümlerin tedbir alınarak ertelenebileceğini göstermiştir. Ölüm de ölüme sebep olan unsurların geçici bir süre ortadan kaldırılması da ilahi yasanın içindedir. Vahiy de bu gerçeği teyit etmektedir:

"Çocuklarınızı yoksulluk korkusuyla öldürmeyin. Biz onlara da size de rızık veririz. Onları öldürmek, şüphesiz büyük bir günahtır. "30

\footnotetext{
${ }^{28}$ el-Kamer 54/49.

29 el-Mülk 67/3.

30 el-İsra $17 / 31$.
} 
Demek ki; irademizi çocukların yaşaması yönünde kullanırsak, Allah'ın izniyle onlar belli bir süre daha yaşayabileceklerdir.

Açlık korkusuyla çocukları öldürmek de, onları öldürmeyip yaşamalarına izin vermek de ilahi yasanın içindedir. Hz. Ömer'in, "Allah'ın kaderinden yine Allah'ın kaderine kaçıyorum,"31 sözü bu konuyu çok net bir şekilde özetlemektedir.

İnsanların işlerini sağlam yapmadıkları için kötü sonuçlar alması da ilahi bir yasadır. Onun için Hz. Peygamber, Allah'ın, işini sağlam ve güzel yapanları seveceğini haber vermiştir:

"Hz. Peygamber bir kabrin başına oturdu ve şöyle demeye başladl: 'Toprağl şuraya ve şuraya koyunuz.' İ̧s bitince de şöyle dedi: 'Gerçekten sonunda onun toprağa karışacağını biliyorum. Ancak Allah, kulu bir iş yaptığında onu sağlam yapmasından hoşlanır. ,",32

Allah hiç kimseye haksızlık etmez. İşini, iyi güzel ve sağlam yapan; iyi ve güzel bir karşılık; kötü, çirkin ve baştan savma yapan ise ona göre bir karşılık bulur. Bununla birlikte insana bütün musibetlerin üstesinden gelebilecek bir imkân da verilmemiştir. Üstesinden gelinemeyen en büyük musibet ise ölümdür.

\section{Sonuç}

Yeryüzünde meydana gelen tüm olaylar, Allah'ın her şeyi kuşatan bilgisinin ve sonsuz hikmetinin bir gereği olarak koymuş olduğu yasalar doğrultusunda gerçekleşir. Hiçbir olay ve hiç kimse bu yasaların dışına çıkamaz. Allah, insana bu yasaları keşfetme imkân ve kabiliyetini vermiştir. $\mathrm{O}$ halde insana düşen bu yasaları keşfetmek için gereken adımları atmaktır.

İnsanın başına gelen iyi ya da kötü her olay, imtihan sırrının bir gereği olmakla birlikte daima belli yasalar çerçevesinde gerçekleşir. Dolayısıyla insan, başına gelen kötülük ya da musibetlerin hangilerinin kendi hatası, hangilerinin de kendi elinde olmayan nedenlerle gerçekleştiğini ayırt edebilecek bir temyiz gücüne sahiptir. Bu yüzden kendi sorumluluğunu kadere fatura etmek için mazeret ileri sürme hakkı onun elinden alınmıştır.

Kısacası her olay bir sonuçtur, dolayısıyla onun bir sebebi vardır. Sebepler engellendiğinde, onlara bağlı olan sonuçlar da engellenmiş olur. Çünkü Allah, ölüm hariç her kötü sonucun engellenebileceği bir çare yaratmıştır. Bu çareleri araştırıp bulması insanın sorumluluğundadır. Diğer önemli bir nokta ise, insanın geçmişte helak edilen kavimlerin durumunda olduğu gibi ilahi cezayı acilen gerektirecek ölçüde büyük suçlar işlememesi ya da onlarda israr etmemesidir.

\footnotetext{
${ }^{31}$ Bir keresinde Hz. Ömer, ordusuyla birlikte Şam yolu üzerinde iken Ebu Ubeyde b. el-Cerrâh'tan orada veba salgını olduğu haberini alınca, ordusuna hemen Medine'ye geri dönme emrini verdi. Bunun üzerine $\mathrm{Hz}$. Ebu Ubeyde, Hz. Ömer'e, “Allah'ın kaderinden mi kaçıyorsun?" diye itiraz etti. Hz. Ömer de ona, "Evet Allah'ın kaderinden yine Onun kaderine kaçıyoruz" diyerek kararlı olduğunu gösterdi. Bu esnada tartışmaya tanıklık eden Abdürrahman b. Avf (r.a), Hz. Peygamber'in veba salgınıla ilgili bir uyarısını hatıllattı. Bu uyarısında Hz. Peygamber, "Bir yerde veba salgını olduğunu duyarsanız, sakın oraya gitmeyin, eğer sizin bulunduğunuz yerde veba salgını çıkarsa, sakın kaçmak için oradan ayrılmayınız" demekteydi. el-Buhârî, es-Sahîh, Bâb: Mâ yüzker fi't-tâ'ûn; hadis no: 5397; el-Müslim, es-Sahîh, Bâb: et-Tâ'ûn; hadis no: 5915; el-Beyhakî, es-Sünen el-Kübrâ, tahkik: Muhammed Abdülkadir Atâ, Beyrut 2003, VII/34.

${ }^{32}$ İsmail b. Ca'fer, Hadîsu Ali b. Hacer es-Sa'dî an İsmail b. Ca'fer el-Medenî, tahkik: es-Süfyanî, Riyad 1998, s. 508.
} 